\title{
Investigation of the Effects of Soaking Time on the Properties of Stainless Steel
}

\author{
Silas Ezedinma Agbokwor ${ }^{*}$, Simeon Ikechukwu Neife \\ Department of Mechanical Engineering, Faculty of Engineering, University of Nigeria Nsukka (UNN), Nsukka, Nigeria
}

\section{Email address:}

chideraogo@yahoo.com (S. E. Agbokwor)

${ }^{*}$ Corresponding author

\section{To cite this article:}

Silas Ezedinma Agbokwor, Simeon Ikechukwu Neife. Investigation of the Effects of Soaking Time on the Properties of Stainless Steel. American Journal of Mechanical and Materials Engineering. Vol. 3, No. 3, 2019, pp. 47-52. doi: 10.11648/j.ajmme.20190303.11

Received: May 5, 2019; Accepted: July 12, 2019; Published: July 31, 2019

\begin{abstract}
An investigation was carried out to determine the effect of soaking time during sensitization on the Mechanical properties of Austenitic stainless steels [1]. The selected samples of AISI 316 and AISI 304 were cut into several pieces so that different amount of sensitization was introduced into the different pieces. To induce sensitization, the samples were heated and soaked at $750^{\circ} \mathrm{C}$ for different time intervals such as 30 minutes, 60 minutes, 180minutes, 300 minutes and 600 minutes followed by water quenching. The resultant samples were tested for Tensile strength, Micro hardness and Macro hardness. It was concluded from the results obtained that the macro and micro hardness of AISI 316 and AISI 304 decreases with increase in soaking time at a constant soaking temperature., However, the macro hardness of AISI 304 decreases more than AISI 316 with increase in soaking time at specified soaking temperature. It was similarly concluded that the tensile strengths AISI 316 and AISI 304 decreases with increase in soaking time at a constant soaking temperature.
\end{abstract}

Keywords: Corrosion, Soaking Time, Soaking Temperature, Sensitization, Austenitic Stainless Steels, Mechanical Properties

\section{Introduction}

Corrosion of materials [2] is the most common and most important failure mechanism in industry. For improved material qualities, polymers and composites were introduced; but despite their introduction, stainless steels still remain very important in structures, because of their strength, stiffness, toughness and tolerance at high temperatures [3]. They are still being used for instance at Catalytic Reformer Unit, Reactor Scallops, Vacuum Distillation Unit, Heat Tubes; at Port Harcourt Refinery-Nigeria. They are also in use at process and utility areas of Mobil producing Nigeria unlimited and Chevron Escravos gas to liquid plants also in Nigeria.

Unfortunately, these facilities structures, which are usually in welded form in order to achieve the desired design, have been observed to experience various debilitating forms of localized corrosion[4-7], that results in loss of millions of dollars each year, because of this corrosion[8,9].Although one of the main reasons why stainless steels are used is corrosion resistance, they do in fact suffer from certain types of corrosionin some environments and care must be taken to select a grade which will be suitable for the application [10]. This corrosion stems from the failure of the passive film, as a result of their microstructural changes at the grain boundaries $[11,12]$ during constructional activities / service operations e.t.c. Why? High temperature for instance; can cause some precipitation of some second phase carbides of varied sizes in the microstructure, resulting in sensitization and consequent decrease in corrosion resistance $[13,14]$. Time and Temperature significantly influences this unusual complex/sensitized microstructure of the steels and hence its properties [15]. Weld decay is common in sensitized stainless steel structures [16].

These unavoidable circumstances could result in a metal with a dendritic and inhomogeneous microstructure having a small amount of delta ferrite and significant segregation of major as well as minor alloying elements at the phase interfaces. The behaviour of these unusual complex microstructure developed is further affected by the steels natural microstructural complexity. The alloys may have many constituent elements and many thermodynamically 
possible phases, and none of these are necessarily uniform in their composition; yet, it is the composition of the alloy in contact with the specific environment at any microscopic point that determines the corrosion resistance of that particular point.

This research therefore, was set out to experimental study the influence of soaking time on the properties of Stainless Steels \{AISI 304 and AISI 316\}. Theinferences from the experimental results / overall analysis would assist;

To establish relationship as observed from the experiments on the various factors (e.g. Alloy composition, Microstructure, Temperature, Time, etc), that may have significant influence on the properties of the steel;

\section{Methodology}

\subsection{Materials}

AISI SS316 and AISI SS304 austenitic stainless steels were selected for this investigation. They are commercial pure samples and were available in the form of pipes and were collected from the ware house of Port Harcourt Refinery Company Ltd, Alese Eleme, Port Harcourt, Rivers

\section{State-Nigeria.}

\subsection{Equipments}

Equipments used for the study included the following: Welding machines, Grinding machines, Cutting machines, Universal milling machine, Manual hand Hacksaw with blade, heat treatment furnace, Mitech Leeb Hardness Tester model MH320 for Macro Hardness Tester, Tukon Micro Hardness Tester, Mitech Leeb Hardness Tester model MH160, Oxford instrument XRF spectrometer model X-Met 7000 with a serial number 711150, Epoxy Resin Ring, Emery Paper.

\subsection{Experimentation}

\subsubsection{Chemical Composition}

The chemical composition of the selected steel samples were determined at Turret Engineering Services Ltd., Port Harcourt using an Oxford instrument XRF spectrometer model X-Met 7000 with serial number 711150 . The details of the chemical composition of the samples are as shown in figures 1 and 2 below.

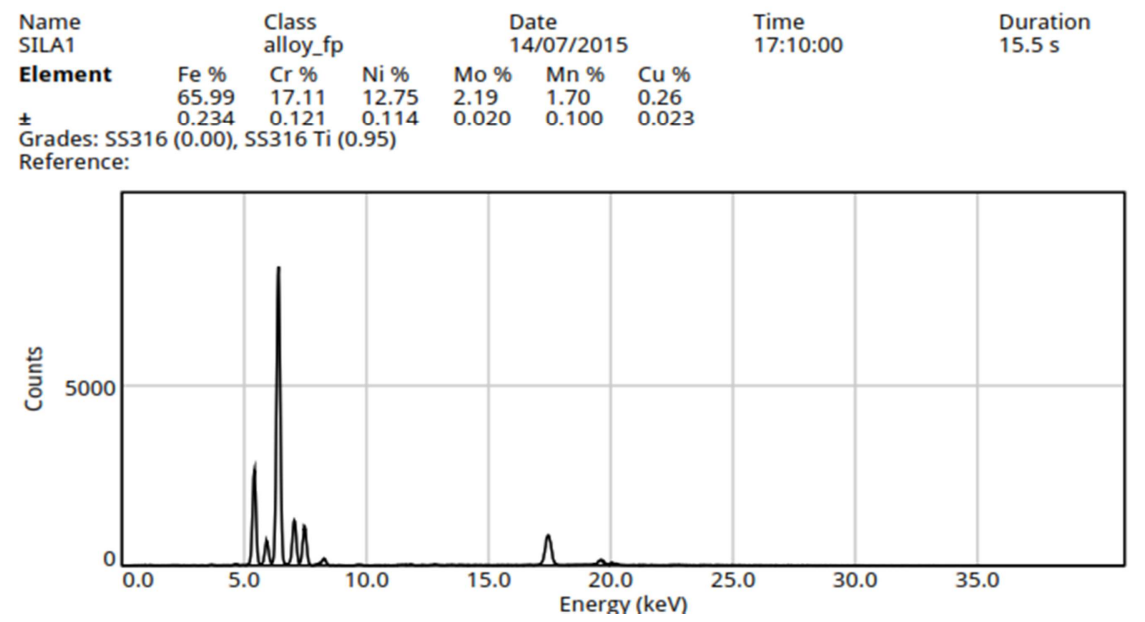

Figure 1. Chemical composition of Austenitic Stainless Steel (AISI 316).

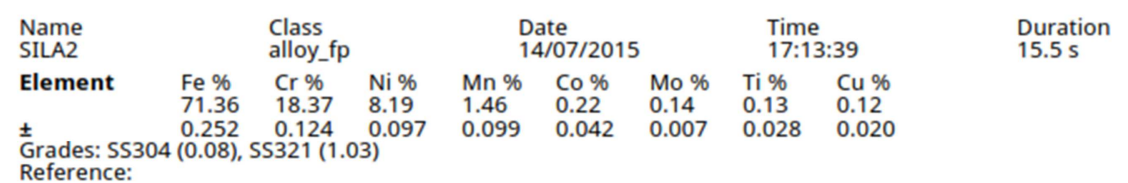
Reference:

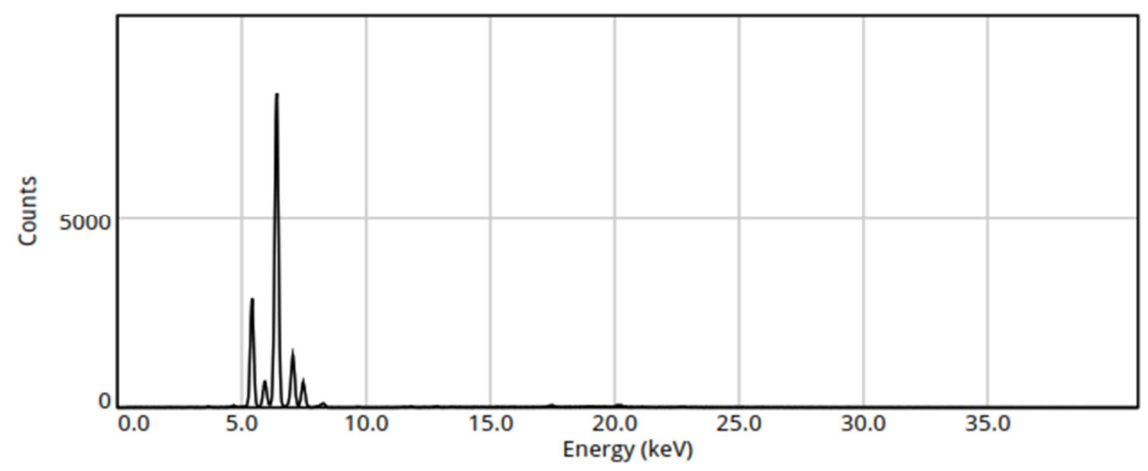

Figure 2. Chemical composition of Austenitic Stainless Steel (AISI 304). 


\section{i. Micro Hardness Determination}

In order to perform the micro hardness test on the samples, they were first roughly polished using belt grinder. Then they were polished with the Emery papers as described in previous descriptions so as to obtain flat surfaces and to avoid anomalies in the results. The micro hardness data of the prepared samples were obtained by using a Tukon Micro hardness Tester. Five (5) readings were taken for each sample to calculate the average hardness.

\section{ii. Macro Hardness Determination}

The macro hardness tests of the samples were performed using Mitech Leeb Hardness Tester model MH320:

\subsubsection{Tensile Strength Determination}

The tensile strength of the samples was determined using Mitech Leeb Hardness Tester model MH160 with capacity for direct reading of the Tensile strength

\section{Results}

The results obtained from the micro hardness, macro hardness and tensile strength tests, after the heat treatment of the samples and the graphic representation are as shown below.

Table 1. Variation of micro hardness (HV) with soaking time of SS 316 AND SS 304.

\begin{tabular}{|c|c|c|c|c|c|c|c|}
\hline \multirow{2}{*}{ Serial No. } & & & SS 316-1 & SS316-2 & SS316-3 & SS316-4 & SS316-5 \\
\hline & & & SS 304-1 & SS 304-2 & SS 304-3 & SS 304-4 & SS 304-5 \\
\hline \multirow{2}{*}{$\begin{array}{l}\text { Micro Hardness } \\
\text { (HV) }\end{array}$} & SS 316 As Received & 247 & 287 & 236 & 250 & 256 & 271 \\
\hline & SS 304 As Received & 277 & 267 & 236 & 256 & 239 & 266 \\
\hline \multicolumn{2}{|c|}{ Soaking Time (Minutes) } & N/A & 30 & 60 & 180 & 300 & 600 \\
\hline
\end{tabular}

Table 2. Variation of macro hardness (HV) with soaking time of SS 316 AND SS 304.

\begin{tabular}{|c|c|c|c|c|c|c|c|}
\hline \multirow{2}{*}{ Serial No. } & & & SS 316-1 & SS316-2 & SS316-3 & SS316-4 & SS316-5 \\
\hline & & & SS 304-1 & SS 304-2 & SS 304-3 & SS 304-4 & SS 304-5 \\
\hline \multirow{2}{*}{ Macro Hardness (HV) } & $\begin{array}{l}\text { SS } 316 \text { As } \\
\text { Received }\end{array}$ & 205 & 191 & 188 & 187 & 181 & 172 \\
\hline & $\begin{array}{l}\text { SS } 304 \text { As } \\
\text { Received }\end{array}$ & 207 & 196 & 182 & 183 & 179 & 174 \\
\hline $\begin{array}{l}\text { Soaking Time } \\
\text { (Minutes) }\end{array}$ & & N/A & 30 & 60 & 180 & 300 & 600 \\
\hline
\end{tabular}

Table 3. Variation of Tensile Strength (MPA) with soaking time of AISI 316 AND AISI 304.

\begin{tabular}{|c|c|c|c|c|c|c|c|}
\hline \multirow{2}{*}{ Serial No. } & & & SS 316-1 & SS316-2 & SS316-3 & SS316-4 & SS316-5 \\
\hline & & & SS 304-1 & SS 304-2 & SS 304-3 & SS 304-4 & SS 304-5 \\
\hline \multirow{2}{*}{ Tensile strength } & $\begin{array}{l}\text { SS } 316 \text { As } \\
\text { Received }\end{array}$ & 611 & 603 & 592 & 566 & 551 & 537 \\
\hline & $\begin{array}{l}\text { SS } 304 \text { As } \\
\text { Received }\end{array}$ & 605 & 589 & 572 & 556 & 511 & 507 \\
\hline Soaking Time (Minutes) & & N/A & 30 & 60 & 180 & 300 & 600 \\
\hline
\end{tabular}

The fifteen figures shown below; are the graphs obtained from the tabulated experimental results; for comparative analysis.

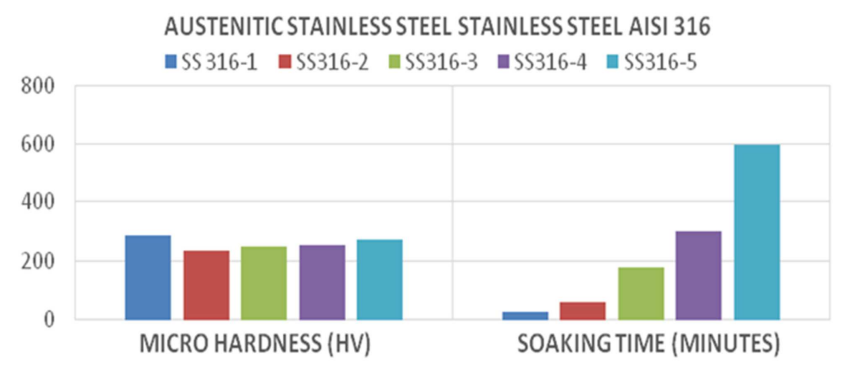

Figure 3. Bar chart showing variation of micro hardness of AISI 316 with variable soaking time.

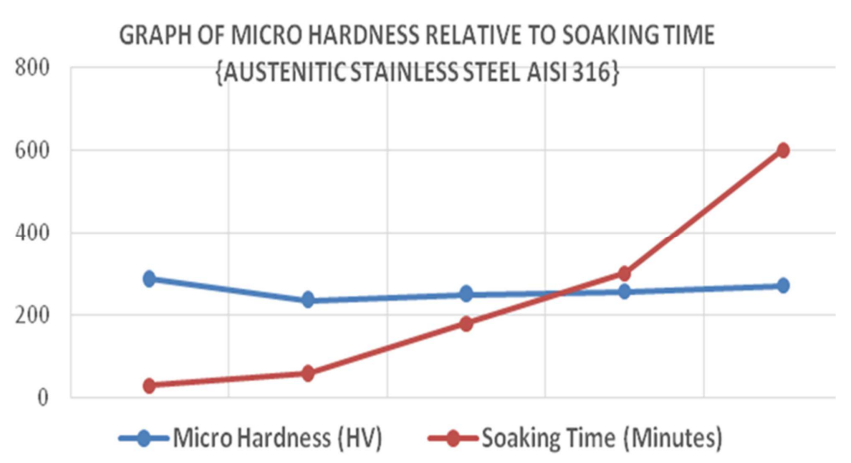

Figure 4. Variation of micro hardness of AISI 316 relative to variable soaking time. 
AUSTENITIC STAINLESS STEEL AISI 304

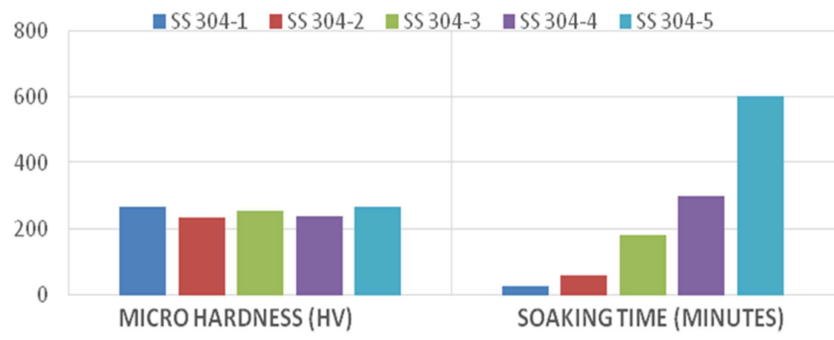

Figure 5. Bar chart showing variation of micro hardness of AISI 304 with variable soaking time.

GRAPH OF MICRO HARDNESS RELATIVE TO SOAKING TIME \{AUSTENITIC STAINLESS STEEL AISI 304\}

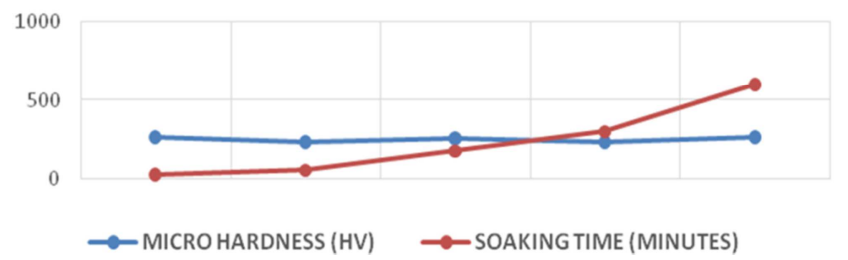

Figure 6. Variation of micro hardness of AISI 304 relative to variable soaking time.

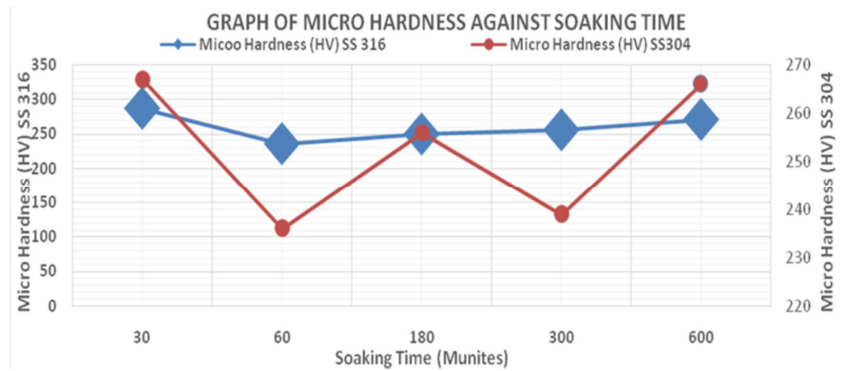

Figure 7. Comparism of variation of micro hardness of AISI316 and AISI 304 with soaking time.

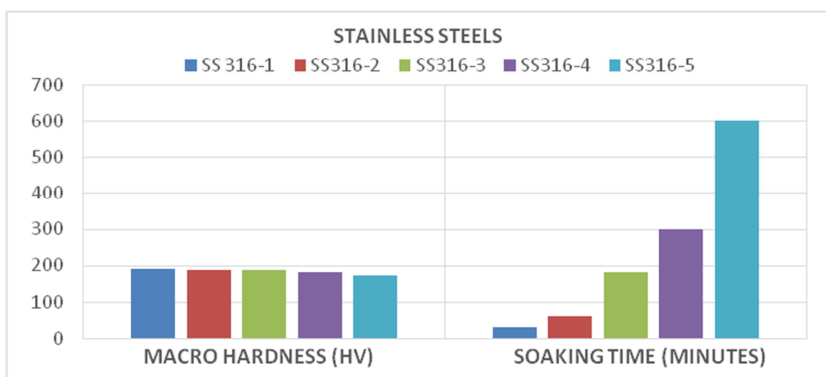

Figure 8. Bar chart showing variation of macro hardness of AISI 316 with variable soaking time.

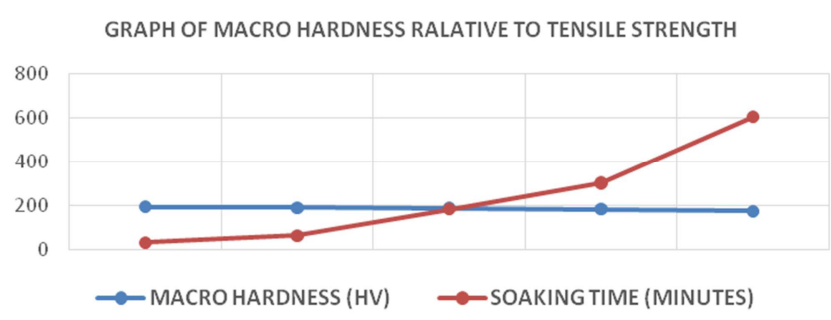

Figure 9. Variation of macro hardness of AISI 316 relative to variable soaking time.

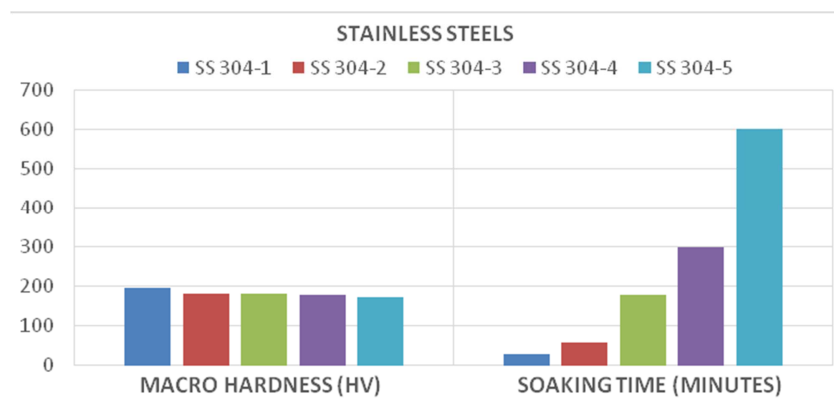

Figure 10. Bar chart showing variation of macro hardness of AISI 304 with variable soaking time.

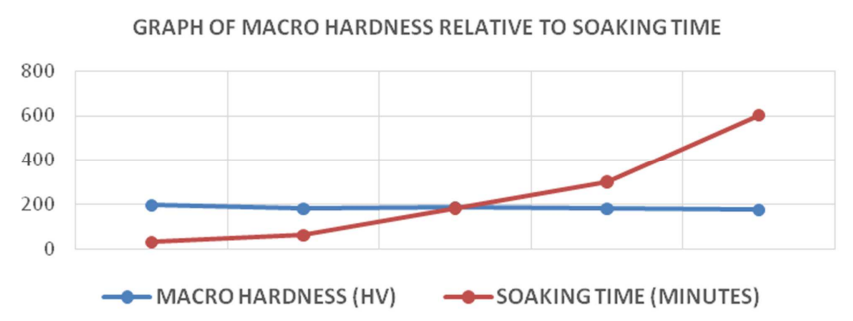

Figure 11. Variation of macro hardness of AISI 304 relative to variable soaking time.

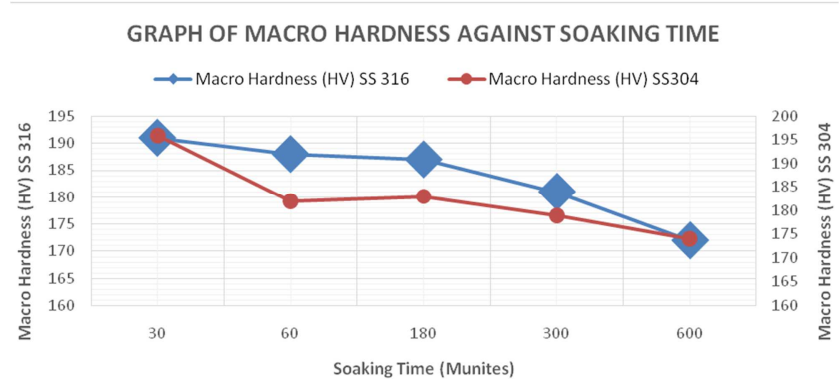

Figure 12. Comparism of variation of macro hardness of AISI316 and AISI 304 with soaking time.

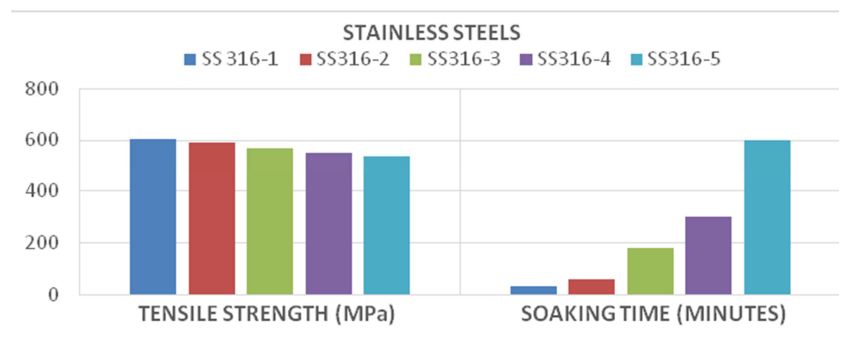

Figure 13. Bar chart showing variation of tensile strength of AISI 316 with variable soaking time.

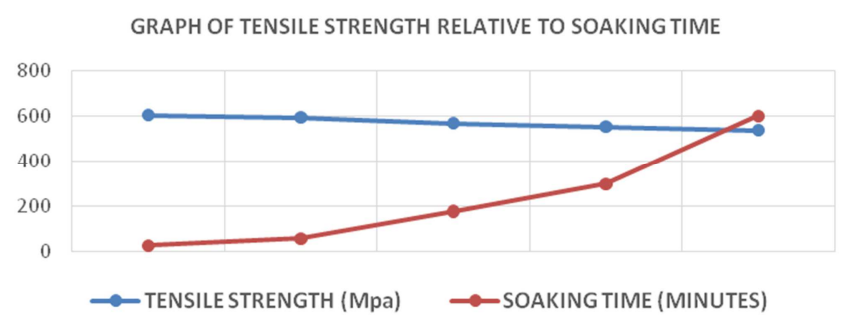

Figure 14. Variation of tensile strength of AISI 316 relative to variable soaking time. 


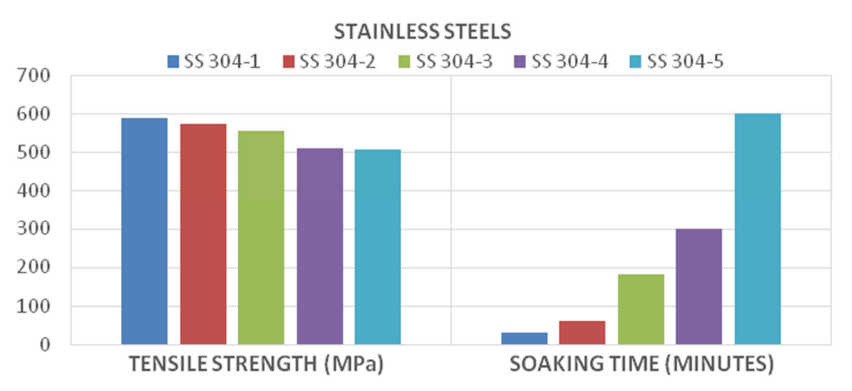

Figure 15. Bar chart showing variation of tensile strength of AISI 304 with variable soaking time.

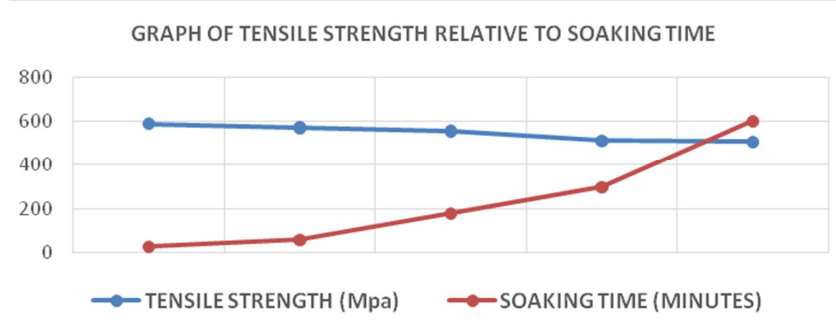

Figure 16. Variation of tensile strength of AISI 304 relative to variable soaking time.

GRAPH OF TENSILE STRENGTH AGAINST SOAKING TIME

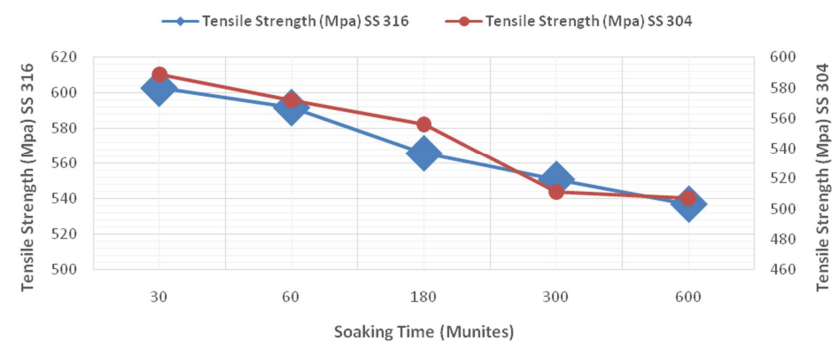

Figure 17. Comparism of variation of Tensile strength of AISI316 and AISI 304 with soaking time.

\section{Discussions}

From Table 1 shown above; careful study of its bar chart and relative relationship of micro hardness and soaking time in figures $\{3,4,5,6\}$; show that AISI 316 and AISI 304 have one common characteristics; i.e. the micro hardness decreases with increase in soaking time at a constant soaking temperature.

In figure 7; between 30 minutes and 60 minutes of the soaking time at constant temperature of $750^{\circ} \mathrm{C}$; micro hardness of AISI 304 decreased sharply. Suddenly from 60 minutes up to 180 minutes, the micro hardness increased sharply once again; but could not reach the initial hardness at 30 minutes soaking time. The micro hardness again decreases sharply, before sharply increasing almost up to the initial hardness of the steel.

However, from the same figure 7; between 30 minutes and 60 minutes of the soaking time, AISI 316 decreased slowly. From 60 minutes, micro hardness increased slowly as the soaking time increases at the same constant soaking temperature

From the above relationship, the microscopic structure, indeed the mechanical strength of AISI 304 is evidently more sensitive to changes in soaking time than that of AISI 316 at variable soaking time at constant temperature.

From Table 2 shown above; careful study of the bar chart and relative relationship of macro hardness and soaking time in figures $\{8,9,10,11\}$; show that AISI 316 and AISI 304 have one common characteristics; i.e. the macro hardness decreases with increase in soaking time at a constant soaking temperature.

In figure 12, the macro hardness of AISI 304 decreases more than AISI 316 with increase in soaking time at specified soaking temperature; i.e. hardness decrease is smaller in AISI 316 than in AISI 304.

Similarly, from Table 3 shown above, careful study of the bar chart and relative relationship of tensile strength and soaking time in figures $\{13,14,15,16\}$; show that AISI 316 and AISI 304 have one common characteristics. That is, tensile strength decreases with increase in soaking time at a constant soaking temperature.

Careful study of the charts, generally showed that the sensitivity of the mechanical properties to changes in soaking time is higher in AISI 304 than in AISI 316. To explain this fact; when heated, carbon diffuses several orders of magnitude more rapidly than chromium due to its relatively high diffusivity. The chromium atoms are almost entirely supplied by the grain boundaries; implying that the grain boundary areas become harder. Slower decrease in strength of AISI 316 is caused by the presence of titanium which has great affinity with carbon.

\section{Conclusion}

Based on the results from this study, the following may be concluded:

a) AISI 316 and AISI 304 have one common characteristic with their tensile strengths decreasing with increase in soaking time at constant soaking temperature.

b) The macro hardness of AISI 316 and AISI 304 decreases with increase in soaking time at a constant soaking temperature.

c) The micro hardness of AISI 316 and AISI 304 decreases with increase in soaking time at a constant soaking temperature.

d) However, the micro hardness of AISI 304 is more sensitive to changes at variable soaking time than AISI 316 , showing the possibility of alpha prime $\left(\alpha^{\prime}\right)$ formation in AISI 304. The microstructures of AISI 316 stainless steels are mainly composed of austenite gamma iron $(\gamma$-Fe) and have FCC structure under the condition of equilibrium solidification.

e) The macro hardness decreases in AISI 304 more than in AISI 316 at specified common condition; showing the possibility of alpha prime $\left(\alpha^{\prime}\right)$ formation $[17,18]$.

f) The presence of alpha prime $\alpha^{\prime}$ (a product of $\delta$-ferrite spinodal decomposition) must have significantly affected the mechanical behaviour by enhancing work 
hardening; because of the presence of its $\mathrm{BCC}$ structure in AISI 304 alloy.

\section{References}

[1] F. Haraszti, T. Kovács: Plastic deformation effect of the corrosion resistance in case of austenitic stainless steel, IOP Conference Series: Materials Science and Engineering 175: Paper 012048.4 (2017).

[2] Pierre R. Roberge: Corrosion Basics-An Introduction, Second Ed. (Houston, TX: NACE International, 2006), pp. 21-22.

[3] National Corrosion Service (NCS) Publication UK. Guides to good practice in corrosion control. (www.npl.co.uk), 2000.

[4] Zheng S, Shibata T, Haruna T: Corrosion Science Journal, 2005, 47, 1049-1061.

[5] Aydogbu GH, Aydinnol MK: Corrosion Science Journal, 2006, 48, 3565-3583.

[6] Seifedine, K (2008): European Journal of Scientific Research, ISSN 1450-216X Vol. 22 No.4, 2008, 508-516.

[7] Pitting Corrosion," NACE International, http://www.nace.org/Pitting-Corrosion (September 28, 2015).

[8] Chen YY, Chou LB, Shih HC, Mater. Chem. Phy., 2006, 96, 37-49.
[9] G.H. Koch, et al., "Corrosion Costs and Preventive Strategies in the United States," Federal Highway Administration, FHWA-RD-01-156, March 2002.

[10] Pramar S: Welding metallurgy 2nd Ed. $\{(2003)$ [New Jersey] $\}$.

[11] Sindou Kou (2003).Welding Metallurgy. 2nd Ed. A John Wiley and Sons, INC. Publication. New Jersey.

[12] F. Haraszti: The bases of corrosion investigation EME press, Múszaki Tudományos Füzetek 21, Cluj Napoca $\{2016\}$ pp. 185-188.

[13] F. Haraszti: Corrosion investigation of steel samples EME press, Múszaki Tudományos Füzetek 21, Cluj Napoca $\{2016\}$ pp.189-192.

[14] Reti T, Kovacs T: A phenomenological method for the prediction of damage accumulation processes under varying external conditions In: Materials Science Forum, 414-415, $\{2003\}$ pp. 317-322.

[15] Parvathavarthini N, Dayal RK, Khatak HS, Shankar V, Journal Nuclear Matererial, 2006, 355, 68-82.

[16] T. Kovács, L. Kuzsella: High Energy Rate Forming Induced Phase Transition in austenitic steel; Journal of Physics Conference-Series 790: Paper 012039. 5 \{2017\}'.

[17] M. Dománkova, et al: The microstructure evolution and its effect on corrosion properties of $18 \mathrm{Cr}-12 \mathrm{Ni}-2,5 \mathrm{Mo}$ Steel, annealed at $500-900^{\circ} \mathrm{C}$, Acta Polytechnica Hungarica, $11(3\{2014\}$ pp. $125-137$. 